http://jmscr.igmpublication.org/home/

ISSN (e)-2347-176x ISSN (p) 2455-0450

crossref DOI: https://dx.doi.org/10.18535/jmscr/v9i8.16

Journal Of Medical Science And Clinical Research

IGM Publication

An official Publication of IGM Publication

\title{
To Study Various Haematological Manifestation in Newly Diagnosed HIV Patient
}

\author{
Authors \\ Dr Arun Kumar ${ }^{1}$, Dr Keshvendra Pratap Singh ${ }^{2}$, Dr Kushal Pal ${ }^{3}$ \\ ${ }^{1}$ Retd. Medical Officer, District Hospital, Jhanshi \\ ${ }^{2.3}$ Junior Resident, S N Medical College, Agra
}

\section{Introduction}

Since the initial cases of HIV/AIDS were identified in June 1981 in Los Angeles, USA, there have been tremendous advances in the field of HIV prevention, diagnosis, care and treatment globally. As per UNAIDS estimates an adult HIV prevalence of $0.8 \%$ and considerable variation between countries, 36.7 million (30.8- 42.9 million) people were estimated to be living with HIV globally. Approximately 1.8 million new infections occurred worldwide and approximately 1.0 million people died of AIDS-related illnesses. The country's epidemic is concentrated among high-risk groups and is heterogeneously distributed with wide geographic variations in the vulnerabilities that drive the epidemic. Even with this low prevalence, India has the third highest burden of HIV in the world with an estimated 2.14 million people living with HIV, 87,000 estimated new infections and 69,000 AIDS-related deaths annually. The first few cases of HIV in the country were detected among female sex workers in Chennai, Tamil Nadu in 1986, followed by reports from other parts of the country.

\section{Material and Methods}

The study was conducted in the Department of Medicine, S N Medical College, Agra. An observational study was conducted in S N Medical College Agra for a period of around 2 years between December 2017 to December 2019. The study includes, Newly diagnosed HIV positive patients, Patients willing to take participation and giving consent for study, patients not taking ART, previously diagnosed asymptomatic patient who are not on art or any treatment.

Patients taking anaemia therapy, taking bone marrow suppressing drugs, Patient not willing for partcipation in study, Patient known case of primary haematological disorder or other disease affecting haematological parameters such patients were excluded from the study.

Completely confidentiality was maintained regarding the identity of subjects by concealing the name and address from study proforma. Prevelance of various haematological disease are observed in patient and its correlation with $\mathrm{cd} 4$ count level.

Total 100 patients were included in the study with HIV positive reports in ART centre and patients in medicine OPD and various investigations were 
carried out such as Haemoglobin [cyanmethhaemoglobin method],Total leucocyte count \& differential leucocyte count [neubauer chamber count],Cd4 count [ flow cytometry ], Platelet count [ammonium oxalate method],Peripheral blood smear [leishman's stain] ,Bleeding and clotting time [dukes method and capillary tube method],Rbc morphology studies [mcv, mch, mchc], Serum iron ,serum ferretin, transferrin, iron binding capacity, Serum B12 and folic acid level, Prothrombin time, Activated partial thromboplastin time, Erythrocyte sedimentaionrate, C- reactive protein, HIV Elisa.

Different data collected \& inserted in microsoft excel for comparing data by chai sqaure test and student $t$ test.A p- value of $<0.05$ is considered stastically signficant in all clinical comparisons at $95 \%$ confidence interval.

\section{Observation and Results}

A total of 100 patients were taken for study from ART centre and hospital those who satisfied the inclusion and exclusion criteria

Table 1: Age and Sex distribution

\begin{tabular}{|c|c|c|c|c|c|c|}
\hline \multirow[t]{2}{*}{ Age (Yrs.) } & \multicolumn{2}{|c|}{ Male } & \multicolumn{2}{|c|}{ Female } & \multicolumn{2}{|c|}{ Total } \\
\hline & No. & $\%$ & No. & $\%$ & No. & $\%$ \\
\hline$\leq 20$ & 2 & 2.74 & 1 & 3.70 & 3 & 3.00 \\
\hline $21-30$ & 18 & 24.66 & 18 & 66.67 & 36 & 36.00 \\
\hline $31-40$ & 36 & 49.32 & 6 & 22.22 & 42 & 42.00 \\
\hline $41-50$ & 13 & 17.81 & 1 & 3.70 & 14 & 14.00 \\
\hline $51-60$ & 4 & 5.48 & 1 & 3.70 & 5 & 5.00 \\
\hline$>60$ & 0 & 0.00 & 0 & 0.00 & 0 & 0.00 \\
\hline Total & 73 & 100.00 & 27 & 100.00 & 100 & 100.00 \\
\hline
\end{tabular}

Table 1 describe age wise and sex wise distribution of study group. Out of 100 patient total males were 73 and females were 27 females. Highest no of males [n =36] between $31-40$ years and females [n $=18$ ] between 21 to 30 years.

Table 2: Hemoglobin

\begin{tabular}{|l|c|c|c|c|c|c|}
\hline \multirow{2}{*}{$\mathrm{Hb}$} & \multicolumn{2}{|c|}{ Male } & \multicolumn{2}{c|}{ Female } & \multicolumn{2}{c|}{ Total } \\
\cline { 2 - 7 } & No. & $\%$ & No. & $\%$ & No. & $\%$ \\
\hline$\leq 6$ & 6 & 8.22 & 6 & 22.22 & 6 & 12.00 \\
\hline$>6-\leq 9$ & 18 & 24.66 & 9 & 33.33 & 27 & 27.00 \\
\hline$>9 \leq 13$ & 40 & 54.79 & 12 & 44.45 & 52 & 52.00 \\
\hline$>13$ & 9 & 12.33 & 0 & 0.00 & 9 & 9.00 \\
\hline Total & 73 & 100.00 & 27 & 100.00 & 100 & 100.00 \\
\hline
\end{tabular}

chi-square $=6.58$

$\mathrm{p}$-value $=0.087$

In $52(52 \%)$ patients, $\mathrm{Hb} \%$ was between 9 and 13 gms\%, 12 out of 100 patients were having $\mathrm{Hb} \%$ below 6 gms \%. In the present study though not statistically significant $(\mathrm{p}=0.087)$.

Table 3: CD4 count and mean $\mathrm{Hb}$

\begin{tabular}{|l|c|c|c|c|c|c|}
\hline \multirow{2}{*}{ CD 4} & \multicolumn{3}{|c|}{ Male } & \multicolumn{3}{c|}{ Female } \\
\cline { 2 - 7 } & $\mathrm{N}$ & Mean & SD & $\mathrm{N}$ & Mean & SD \\
\hline$\leq 200$ & 57 & 9.60 & 2.57 & 20 & 9.60 & 1.58 \\
\hline$>200$ & 16 & 11.00 & 2.04 & 7 & 11.46 & 0.90 \\
\hline t-value & \multicolumn{3}{|c|}{2.005} & \multicolumn{3}{c|}{2.929} \\
\hline p-value & \multicolumn{3}{|c|}{0487} & \multicolumn{3}{c|}{0.0072} \\
\hline
\end{tabular}

Of the 77 cases having CD4 count less than 200, 77 cases were having $\mathrm{Hb} \%$ less than normal. In the present study though statistically significant $(\mathrm{p}=0.0487]$ 
Table 4: CD4 count and TLC

\begin{tabular}{|l|c|c|c|c|c|c|}
\hline \multirow{2}{*}{ CD 4} & \multicolumn{6}{|c|}{ Male } \\
\cline { 2 - 7 } & \multicolumn{2}{|c|}{$<4000$} & \multicolumn{2}{c|}{$4000-11000$} & \multicolumn{2}{c|}{$>11000$} \\
\cline { 2 - 7 } & No. & $\%$ & No. & $\%$ & No. & $\%$ \\
\hline$\leq 200(\mathrm{~N}=57)$ & 28 & 49.12 & 24 & 42.11 & 5 & 8.77 \\
\hline$>200(\mathrm{~N}=16)$ & 4 & 25.00 & 10 & 62.50 & 2 & 12.50 \\
\hline
\end{tabular}

chi-square $=2.96$

p-value $=0.228$

The total leucocyte count ranged from 1900 cells $/ \mathrm{mm}^{3}$ to 11000 cells $/ \mathrm{mm}^{3}$, with prevalence of leucopenia in males of $49.12 \%$. In the present study though not statistically significant $(\mathrm{p}<0.228)$.

Table 5: CD4 count and Platelets (Male)

\begin{tabular}{|l|c|c|c|c|c|c|}
\hline \multirow{2}{*}{ CD 4} & \multicolumn{6}{|c|}{ Platelets } \\
\cline { 2 - 7 } & \multicolumn{2}{|c|}{$<1.5$} & \multicolumn{2}{c|}{$1.5-4.0$} & \multicolumn{2}{c|}{$>4.0$} \\
\cline { 2 - 7 } & No. & $\%$ & No. & $\%$ & No. & $\%$ \\
\hline$\leq 200(\mathrm{~N}=57)$ & 18 & 31.58 & 36 & 63.16 & 3 & 5.26 \\
\hline$>200(\mathrm{~N}=16)$ & 3 & 18.75 & 12 & 75.00 & 1 & 6.25 \\
\hline
\end{tabular}

Chi square $=1.00$

p- value $=0.605$

The platelet count ranges from 0.7 to 4.5 lakhs/cmm3 with prevalence of thrombocytopenia of about $31.58 \%$ in male patient with CD4 count $<200$ and $18.75 \%$ with CD4 $>200$. In the present study though not statistically significant $(\mathrm{p}<0.605)$

Table 6: CD4 count and Platelets (female)

\begin{tabular}{|l|c|c|c|c|c|c|}
\hline \multirow{3}{*}{ CD 4} & \multicolumn{6}{|c|}{ Platelets } \\
\cline { 2 - 7 } & \multicolumn{2}{|c|}{$<1.5$} & \multicolumn{2}{c|}{$1.5-4$} & \multicolumn{2}{c|}{$>4$} \\
\cline { 2 - 7 } & No. & $\%$ & No. & $\%$ & No. & $\%$ \\
\hline$\leq 200(\mathrm{~N}=20)$ & 7 & 35.00 & 13 & 65.00 & 0 & 0.00 \\
\hline$>200(\mathrm{~N}=7)$ & 1 & 14.29 & 6 & 85.71 & 0 & 0.00 \\
\hline
\end{tabular}

Chi -square $=1.07$

p-value $=0.302$

The platelet count ranges from 0.7 to 4.5 lakhs/cmm3 with prevalence of thrombocytopenia of about $35.00 \%$ in male patient with CD4 count $<200$ and $14.29 \%$ with CD4 >200. In the present study though not statistically significant $(\mathrm{p}<0.302)$

Table 7: CD4 count and mean PT

\begin{tabular}{|l|c|c|c|c|c|c|}
\hline \multirow{2}{*}{ CD 4} & \multicolumn{3}{|c|}{ Male } & \multicolumn{3}{c|}{ Female } \\
\cline { 2 - 7 } & $\mathrm{N}$ & Mean & SD & N & Mean & SD \\
\hline$\leq 200$ & 57 & 14.66 & 2.86 & 20 & 14.65 & 2.61 \\
\hline$>200$ & 16 & 14.47 & 3.87 & 7 & 14.27 & 2.50 \\
\hline t-value & \multicolumn{3}{|c|}{-0.217} & \multicolumn{3}{c|}{-0.335} \\
\hline p-value & \multicolumn{3}{|c|}{0.8292} & \multicolumn{3}{c|}{0.7405} \\
\hline
\end{tabular}

Mean of PT in male patient with CD4 count <200 is 14.66 and 14.65 with CD4 <200 in male and females respectively. In the present study though not statistically significant $(\mathrm{p}<0.940$ statistically significant $(\mathrm{p}=$ 0.756).

Table 8: CD4 count and aPTT (Male)

\begin{tabular}{|l|c|c|c|c|c|c|}
\hline \multirow{2}{*}{ CD 4} & \multicolumn{9}{|c|}{ aPTT } \\
\cline { 2 - 7 } & \multicolumn{2}{|c|}{$<30$} & \multicolumn{2}{c|}{$30-40$} & \multicolumn{2}{c|}{$>40$} \\
\cline { 2 - 7 } & No. & $\%$ & No. & $\%$ & No. & $\%$ \\
\hline$\leq 200(\mathrm{~N}=57)$ & 4 & 7.02 & 48 & 84.21 & 5 & 8.77 \\
\hline$>200(\mathrm{~N}=16)$ & 1 & 6.25 & 14 & 87.50 & 1 & 6.25 \\
\hline
\end{tabular}
$\begin{aligned} & \text { chi-square }=0.123 \\
& \text { p-value }=0.940\end{aligned}$


Prevalence of aPTT $>40$ in male patient with CD4 count $<200$ is $8.77 \%$ and $6.25 \%$ with CD $4>200$. In the present study though not statistically significant $(\mathrm{p}<0.940)$

Table 9: CD4 count and aPTT (female)

\begin{tabular}{|l|c|c|c|c|c|c|}
\hline \multirow{2}{*}{ CD 4} & \multicolumn{6}{|c|}{ Aptt } \\
\cline { 2 - 7 } & \multicolumn{2}{|c|}{$<30$} & \multicolumn{2}{c|}{$30-40$} & \multicolumn{2}{c|}{$>40$} \\
\cline { 2 - 7 } & No. & $\%$ & No. & $\%$ & No. & $\%$ \\
\hline$\leq 200(\mathrm{~N}=20)$ & 1 & 5.00 & 18 & 90.00 & 1 & 5.00 \\
\hline$>200(\mathrm{~N}=7)$ & 1 & 14.28 & 5 & 71.43 & 1 & 14.28 \\
\hline
\end{tabular}

chi-square $=1.42$

p-value $=0.492$

Prevalence of a PTT>40 in female patient with CD4 count $<200$ is $5.00 \%$ and $14.28 \%$ with CD4 $>200$. In the present study though not statistically significant $(\mathrm{p}<0.94)$

\section{Discussion}

The patient age in the present study ranged from 12 to 57 years. Coming to the age distribution about $78 \%$ of the patients fell in the age group of 21 to 40 years, which as per the fact is the sexually active part of life as well as highly productive age group. In the present study compared to male age distribution females were younger, $42 \%$ of them were between 31 to 40 years of age group. There was statistical significance to age and sex distributionAs expected a high incidence of anemia is noted in the present study which is in accordance with other previous studies. The multifactorial origin of anemia in HIV disease complicates its differential diagnosis and treatment. The commonest anemia in the present study was microcytic hypochromic anemia (62\%). Normocytic normochromic anemia was found in $26 \%$ in the present study. 12 cases of each of macrocytic normochromic anemia. There was no statistical significance in the incidence of particular anemia with particular sex (p-value $=$ 0.660 for males, $\mathrm{p}$-value $=0.534$ for females).

In correlation of different type of anaemias with respect to clinical stage there was increased possibility of microcytic hypochromic anaemia as clinical stage worsened. According to Spivak JL et al- $^{[1]}$ anemia was found in $18 \%$ of HIV seropositive patients, $50 \%$ of patients with AIDS related complex, and $75 \%$ of those with AIDS. Murphy MF et al- ${ }^{[2]}$ the incidence of lymphopenia, neutropenia and thrombocytopenia in patients with AIDS was $75 \%, 20 \%$ and $30 \%$ respectively and in patients with asymptomatic HIV positive patients the incidence was $15 \%, 0 \%$ and $0 \%$ respectively.

The study was designed to ascertain the basic coagulation defects in HIV infected individuals with routine parameters like platelet count, prothrombin time and aPTT with respect to their CD4 counts. The study group $(\mathrm{n}=100)$. Among the 100 HIV infected cases, 73 cases were males and 27 were females. The most of the HIV infected cases was between 20 - 40 years.

In our study, we found that PT and APTT were significantly increased in treatment positive HIV individuals. This finding is concordant with Omoregie et al ${ }^{[3]}$, who also reported increased PT and APTT in HIV patients. Eefje Jong et al ${ }^{[4]}$, also reported prolonged PT and APTT in 6\% and $2 \%$ of their study subjects respectively. We also found a significant decrease in platelet count in HIV patients. Omoregie et al. ${ }^{[3]}$ also observed a similar reduction in platelet count in HIV cases compared to controls. The cause for decreased platelet count is due to increased platelet destruction by depositio.

On comparing the platelet count, PT and aPTT in HIV positive cases with CD4 count < 200cells $/ \mathrm{mm}^{3}$ and those with count > 200 cells $/ \mathrm{mm}^{3}$, we found that only aPTT is significantly higher in HIV cases with CD4 count less than 200 cells $/ \mathrm{mm}^{3}$. $\mathrm{n}$ of circulating immune complexes on platelets. Ifeanyichukwu M et al. ${ }^{[5]}$ found significantly increased aPTT in HIV cases not on ART compared with HIV cases on ART . 


\section{Conclusion}

In the present study, out of 100 patients, the commonest haematological manifestations found were anemia, leucopenia and thrombocytopenia.

Anaemia was most common abnormality followed by leucopenia.

The frequency and severity of these hematological manifestations increased with decline in CD4 count and had got significant impact on clinical outcomes and quality of life.

Hence all HIV patients should be investigated for hematological abnormalities and treated accordingly to reduce morbidity and mortality. Coagulation parameter were also affected so they should considered in susceptible patients.

\section{References}

1. Spivak JL, Bender BS, Quin TC. Hematological abnormalities in the acquired immune deficiency syndrome. Am J Med 1984;77:224-8.

2. Murphy MF, Metcalfe P, Waters AH. Incidence of neutropenia and thrombocytopenia in patients with human immunodeficiency virus infection. $\mathrm{Br} \mathrm{J}$ Haematol 1987; 91-102.

3. Omoregie $\quad \mathrm{R}^{1}$, Osakue SI, Ihemeje $\mathrm{V}$, Omokaro EU, Ogeferet HO Correlation of CD4 count with platelet count, prothrombin time and activated partial thromboplastin time among HIV patients in Benin City, Nigeria West Indian Med J 2009 Nov;58(5):437-40.

4. Jong E, Meijers J, Van Gorp E, Spek A, Mulder J. Markers of inflammation and coagulation indicate a prothrombotic state in HIV-infected patients with long-term use of antiretroviral therapy with or without abacavir. AIDS Res Ther. 2010;7(1):9
5. Ifeanyichukwu M, Ezeah S, Onyenekwe C, Amilo G, Ezeugwunn5IP, Ifediata FC, et al. Effects of malaria, hiv infection and antiretroviral therapy on some coagulation profiles. IOSJPBS. 2012;1(5):24-49. 